\title{
Supervivencia en pacientes con neumonía grave por SARS-CoV-2 con sobreinfección en una Unidad de Cuidados Intensivos
}

Survival in patients with severe SARS-CoV-2 pneumonia with superinfection in an Intensive Care Unit Sobrevivência em pacientes com pneumonia grave por SARS-CoV-2 com superinfecção em uma Unidade de Terapia Intensiva

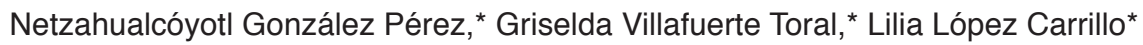

\section{RESUMEN}

Introducción: La sobreinfección en pacientes con síndrome respiratorio agudo severo por coronavirus 2 (SARS-CoV-2) no está completamente entendida y requiere ser atendida para evitar el uso excesivo de antibióticos.

Material y métodos: Estudio observacional, retrospectivo, longitudinal, comparativo, en pacientes con neumonía grave por SARS-CoV-2. Se calculó la probabilidad de supervivencia individual acumulada a lo largo de 90 días con el método de Kaplan Meier, en grupos con sobreinfección o ausencia de desarrollo de microorganismos aislados mediante cultivos de secreción bronquial, hemocultivos central y periférico, y urocultivos.

Resultados: Se reclutaron 82 pacientes, 21 (25.6\%) presentaron crecimiento bacteriano o fúngico en cultivos de secreción bronquial, ocho $(9.7 \%)$ presentaron crecimiento bacteriano en hemocultivos periféricos, cinco $(6 \%)$ tuvieron desarrollo bacteriano en hemocultivos centrales, y $16(19.5 \%)$ presentaron crecimiento bacteriano o fúngico en urocultivos. La supervivencia en estos pacientes fue menor, sin ser significativa, con respecto a quienes no tuvieron sobreinfección ( $p=0.352,0.280,0.119,0.302$ respectivamente).

Conclusión: La sobreinfección en los pacientes con neumonía grave por SARS-CoV-2 no demostró ser un factor asociado a menor supervivencia y aunque la prevalencia de sobreinfección no es despreciable, no hay evidencia suficiente para respaldar el uso generalizado de antibióticos empíricos.

Palabras clave: SARS-CoV-2, sobreinfección, ventilación mecánica, supervivencia

\section{ABSTRACT}

Introduction: Superinfection in patients with severe acute respiratory syndrome by coronavirus 2 (SARS-CoV-2) is not completely understood and requires attention to avoid the excessive use of antibiotics.

Material and methods: Observational, retrospective, longitudinal, comparative study in patients with severe SARS-CoV-2 pneumonia. The accumulated probability of individual survival over 90 days was calculated with the Kaplan Meier method, in groups with superinfection or absence of development of isolated microorganisms using cultures of bronchial secretion, central and peripheral blood cultures, and urine cultures.

Results: Eighty-two patients were recruited, 21 (25.6\%) presented bacterial or fungal growth in cultures of bronchial secretion, eight (9.7\%) presented bacterial growth in peripheral blood cultures, five (6\%) had bacterial development in central blood cultures, and 16 (19.5\%) presented bacterial or fungal growth in urine cultures. Survival in these patients was lower, without being significant, with respect to those who did not have superinfection, ( $p=0.352,0.280,0.119,0.302$ respectively). Conclusion: Superinfection in patients with severe SARS-CoV-2 pneumonia has not been shown to be a factor associated with lower survival, and although the prevalence of superinfection is not negligible, there is insufficient evidence to support the generalized use of empirical antibiotics.

Keywords: SARS-CoV-2, superinfection, mechanical ventilation, survival.

\section{RESUMO}

Introdução: A superinfecção em pacientes com síndrome respiratória aguda grave pelo coronavírus 2 (SARS-CoV-2) não é totalmente compreendida e requer atenção para evitar o uso excessivo de antibióticos.

\section{* Centro Médico ISSEMyM Toluca, México.}

Recibido: 20/01/2021. Aceptado: 09/02/2021.

Citar como: González PN, Villafuerte TG, López CL. Supervivencia en pacientes con neumonía grave por SARS-CoV-2 con sobreinfección en una Unidad de Cuidados Intensivos. Med Crit. 2021;35(5):237-242. https://dx.doi.org/10.35366/102351

www.medigraphic.com/medicinacritica
Material e métodos: Estudo observacional, retrospectivo, longitudinal e comparativo em pacientes com pneumonia grave por SARS-CoV-2. A probabilidade acumulada de sobrevida individual em 90 dias foi calculada pelo método de Kaplan Meier, nos grupos com superinfecção ou ausência de desenvolvimento de microrganismos isolados por meio de cultura de secreção brônquica, hemocultura central e periférica e cultura de urina.

Resultados: Foram recrutados 82 pacientes, 21 (25.6\%) apresentaram crescimento bacteriano ou fúngico em culturas de secreção brônquica, 8 (9.7\%) apresentaram crescimento bacteriano em hemoculturas periféricas, 5 (6\%) apresentaram desenvolvimento bacteriano em hemoculturas centrais, e 16 (19.5\%) apresentaram crescimento bacteriano ou fúngico nas culturas de urina. A sobrevida nesses pacientes foi menor, sem ser significativa, em comparação com aqueles que não tiveram superinfecção, $(p=0.352,0.280,0.119,0.302$ respectivamente).

Conclusão: A superinfecção em pacientes com pneumonia grave por SARS-CoV-2 não demonstrou ser um fator associado a menor sobrevida e, embora a prevalência de superinfecção não seja desprezível, não há evidências suficientes para apoiar o uso generalizado de antibióticos empíricos.

Palavras-chave: SARS-CoV-2, superinfecção, ventilação mecânica, sobrevivência.

\section{INTRODUCCIÓN}

La sobreinfección bacteriana se identifica comúnmente en infecciones virales del tracto respiratorio como la influenza y son una causa importante de morbilidad y mortalidad, que requieren un diagnóstico oportuno y terapia antibacteriana. ${ }^{1-3}$ Aunque es muy variable, se ha informado que la coinfección bacteriana en pacientes con influenza grave es tan alta como $20-30 \%^{3,4}$ y está asociada con una mayor severidad de la enfermedad, mayor uso de recursos de salud y un incremento del riesgo de muerte. ${ }^{5}$

La prevalencia, incidencia y características de las infecciones bacterianas en pacientes con síndrome respiratorio agudo severo por coronavirus 2 (SARSCoV-2) no están completamente entendidos y se ha planteado como una importante laguna de conocimientos. ${ }^{6,7}$

Si bien, los antibióticos son ineficaces para el tratamiento de COVID-19, se indican por una variedad de razones, esto incluye la dificultad para descartar la coinfección bacteriana en el momento de la presentación, pero también la posibilidad de una infección bacteriana secundaria durante el curso de la enfermedad. Extrapolando las preocupaciones sobre un aumento de la mortalidad en pacientes con sobreinfección bacteriana durante las pandemias de influenza, varias guías reco- 
miendan el uso de antibióticos empíricos para pacientes con COVID-19 grave..$^{8,9}$ Debido a la gravedad inicial de estos pacientes junto con la complejidad de descartar una coinfección bacteriana asociada con hallazgos clínicos, biológicos o radiológicos, más de $90 \%$ de los pacientes críticamente enfermos con SARS-CoV-2 reciben terapia antibiótica empírica al ingreso a la Unidad de Cuidados Intensivos (UCI). ${ }^{10-13}$

Sin embargo, esta suposición genera preocupaciones sobre el uso excesivo de antibióticos y el daño posterior asociado con la resistencia bacteriana. Conocer la proporción de pacientes con COVID-19 con coinfección bacteriana respiratoria y los patógenos culpables es crucial para tratar a los pacientes con COVID-19 ayudando a garantizar el uso responsable de antibióticos, minimizando las consecuencias negativas del uso excesivo. ${ }^{6}$

\section{MATERIAL Y MÉTODOS}

Tipo de estudio. Observacional, retrospectivo, longitudinal, comparativo.

Diseño del estudio. Se realizó una hoja piloto de recolección de datos, la cual se llenó durante dos semanas, tiempo en que se realizaron ajustes en el orden de llenado y se incorporaron datos útiles para el propósito del estudio. Después se procedió a recabar la información contenida en expedientes de pacientes que estuvieron hospitalizados en la UCI durante los siguientes cuatro meses de iniciado el estudio. Al cabo de 90 días, si el paciente ya no estaba hospitalizado se realizó una llamada vía telefónica a su domicilio para verificar su estatus.

Universo de trabajo. Expedientes clínicos de pacientes ingresados a la UCI del Centro Médico ISSEMyM Toluca.

\section{Criterios de inclusión}

1. Pacientes que ingresaron a la $\mathrm{UCI}$ con diagnóstico de SDRA moderado a grave secundario a neumonía por SARS-CoV-2 con requerimiento de ventilación mecánica, en el periodo comprendido de abril a julio de 2020.

\section{Criterios de exclusión}

1. Pacientes que no son derechohabientes e ingresaron a la $\mathrm{UCl}$ en tanto se logró el traslado a su unidad de adscripción.

2. Pacientes que ingresaron provenientes de otras unidades de terapia intensiva.

3. Pacientes que ingresaron a la $\mathrm{UCI}$ con una mortalidad calculada mayor a $90 \%$ de acuerdo a la escala de pronóstico SOFA (Sepsis related Organ Failure Assessment).
4. Pacientes cuyo expediente se encontró incompleto.

5. Pacientes en quienes el seguimiento a 90 días no fue posible.

6. Pacientes que permanecieron en la UCI por menos de 72 horas.

Hipótesis: la supervivencia es mayor en pacientes con neumonía grave por SARS-CoV-2 que no desarrollan crecimiento bacteriano o fúngico en cultivos de secreción bronquial, hemocultivos central y periférico y en urocultivos.

Objetivo principal: determinar qué supervivencia tienen los pacientes con neumonía grave por SARSCoV-2 con sobreinfección pulmonar.

Objetivos secundarios:

1. Determinar cuáles son los microorganismos que más comúnmente sobreinfectan a pacientes con neumonía grave por SARS-CoV-2.

2. Qué supervivencia tienen los casos con neumonía grave por SARS-CoV-2 con hemocultivos centrales y periféricos positivos.

3. Qué supervivencia tienen los casos con neumonía grave por SARS-CoV-2 con urocultivos positivos.

Operacionalización de variables: el síndrome respiratorio agudo severo secundario a coronavirus 2 (SARSCoV-2) fue definido como la relación $\mathrm{PaO}_{2} / \mathrm{FiO}_{2}<200$ $\mathrm{mmHg}$ con PEEP $>5 \mathrm{cmH}_{2} \mathrm{O}$ en un paciente con RTPCR para coronavirus-19 positiva. Las muestras para cultivos se tomaron al ingreso a la Unidad de Cuidados Intensivos, la muestra de esputo se tomó mediante circuito cerrado de aspiración, las muestras de sangre fueron tomadas a partir de la punción de una vena periférica y desde un acceso venoso central para su depósito en un set consistente de un vial aeróbico y uno anaeróbico. La muestra de orina fue tomada una vez instalada la sonda transuretral.

Límite de tiempo y espacio: se realizó en el periodo comprendido del 21 de abril al 31 de julio de 2020. En expedientes clínicos de casos con derechohabiencia que ingresaron a la UCI del Centro Médico ISSEMyM Toluca.

Análisis estadístico: los pacientes fueron categorizados con base en su gravedad al momento del ingreso a terapia intensiva utilizando la escala SOFA, analizándose los factores de riesgo prevalentes mediante estadística descriptiva para después dar seguimiento a las variables fisiológicas y bioquímicas de cada uno de los casos durante el tiempo que permanecieron en cuidados intensivos. Se analizaron los días de ventilación mecánica, estancia en terapia intensiva y estancia hospitalaria en general. Una vez con la base de datos completa, se calculó la probabilidad de supervivencia individual acumulada a lo largo del tiempo con el méto- 
do de Kaplan Meier en pacientes con neumonía grave por SARS-CoV-2, con base en la presencia o ausencia de crecimiento de microorganismos en los cultivos de secreción bronquial, hemocultivos central y periférico, y urocultivo; mediante la prueba log rank se identificó si existía diferencia significativa de la supervivencia entre grupos. Se utilizó el programa SPSS versión 23.

Aspectos éticos: el estudio se registró en la Unidad de Educación e Investigación y fue aprobado por los integrantes del Comité de Investigación en Salud y Ética en Investigación del Centro Médico ISSEMyM Toluca en la sesión ordinaria número 223 celebrada el 13 de enero de 2021, cuyo registro quedó asentado en el oficio 207C0401010201S/017/2021. La aplicación del instrumento se realizó en las instalaciones del propio hospital, específicamente en el Servicio de Terapia Intensiva de acuerdo con los principios éticos establecidos en la $18^{\mathrm{a}}$ Asamblea Médica Mundial (Helsinki, 1964), la información fue de carácter confidencial, sin utilizar los nombres propios que contenían los expedientes elegidos. Por tratarse de un estudio de tipo observacional, sin ningún tipo de intervención, no requirió de consentimiento informado.

\section{RESULTADOS}

Durante el tiempo de estudio se reclutaron un total de 82 pacientes con diagnóstico de SARS-CoV-2, 59 hombres (72\%) y 23 mujeres (28\%), relación $2.5: 1$, la edad osciló entre los 25 y 65 años, con una media de 45.8 y una mediana de 46.5 años, $47.6 \%$ de la población estudiada padecía algún grado de obesidad, $37.8 \%$ diabetes mellitus tipo 2, 15.9\% hipertensión arterial sistémica, 8.5\% tenían antecedente de tabaquismo y $3.7 \%$ una enfermedad pulmonar previa. Con respecto a la gravedad con la que ingresaron a cuidados intensivos, la media en la puntuación de la escala SOFA fue de 5.8, con una mediana de 6 y una desviación estándar de 1.639, con un mínimo de 3 y un máximo de 11 . Con respecto a los días de ventilación mecánica, la media se ubicó en 13.3 días, con una mediana de 11 días, con un mínimo de tres y un máximo de 35 días; con respecto a la estancia en terapia intensiva, la media fue de 15.4 días con una mediana de 12 días, con un mínimo de cinco y un máximo de 45 días, con una estancia hospitalaria final que osciló entre seis y 61 días (media de 24.7 y mediana de 22.5 días).

Del total de pacientes estudiados, 61 (74.3\%) no tuvieron desarrollo de microorganismos en los cultivos de secreción bronquial, mientras que 21 (25.6\%) sí desarrollaron crecimiento bacteriano o fúngico. En el seguimiento a 90 días, se presentaron en el primer grupo 21 defunciones (con una supervivencia de $65.6 \%$ ) y en el segundo grupo 11 (con una supervivencia de 47.6\%) (Figura 1). La supervivencia acumulada entre los individuos de ambos grupos fue de $61 \%$ en el seguimiento a 90 días.
Dentro del grupo que no tuvo crecimiento de microorganismos en los cultivos de secreción bronquial, el tiempo promedio en que ocurrió la defunción fue de 64.4 días, mientras que en el grupo en quienes sí hubo desarrollo bacteriano o fúngico fue de 58.8 días, siendo para éstos el valor de $\mathrm{p}$ de la prueba de log rank de 0.352 , la cual al ser mayor de 0.05 indica que no hay evidencia estadísticamente significativa para rechazar la hipótesis nula de igualdad de supervivencia en ambos grupos (el comportamiento de supervivencia es el mismo en ambos grupos).

Los microorganismos más frecuentemente aislados en los cultivos de secreción bronquial fueron en orden de frecuencia: Pseudomona aeruginosa (6.1\%), Candida albicans (4.9\%), Acinetobacter baumannii (3.7\%), E. coli BLEE (betalactamasas de espectro extendido) (3.7\%), Stenotrophomonas maltophilia (2.4\%), seguidos de Candida parapsilosis, Enterococcus faecalis, Pseudomonas fluorescens, Serratia marcescens, Klebsiella pneumoniae ssp. y Streptococcus thoraltensis.

Se analizó la supervivencia entre los casos con base en el crecimiento bacteriano en hemocultivos periféricos, de los 82 pacientes, ocho (9.7\%) presentaron crecimiento bacteriano, grupo en el que la superviven-

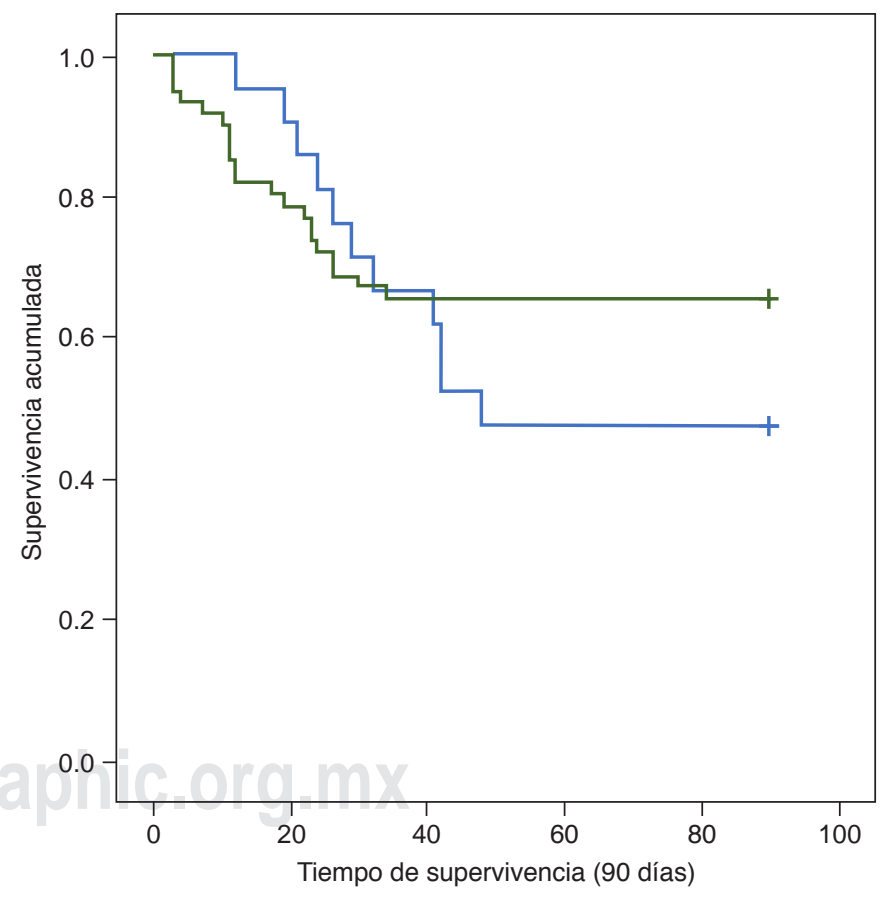

Cultivo de secreción bronquial $\begin{array}{ll}\neg \text { Con desarrollo } & + \text { Con desarrollo-censurado } \\ \neg \text { Sin desarrollo } & + \text { Sin desarrollo-censurado }\end{array}$

Figura 1: Curva de Kaplan Meier que muestra mayor supervivencia en el grupo de pacientes con neumonía grave por SARS-CoV-2 que no presentaron sobreinfección pulmonar (verde) comparado con quienes tuvieron desarrollo de microorganismos en el cultivo de secreción bronquial (azul) $(p=0.352)$. 


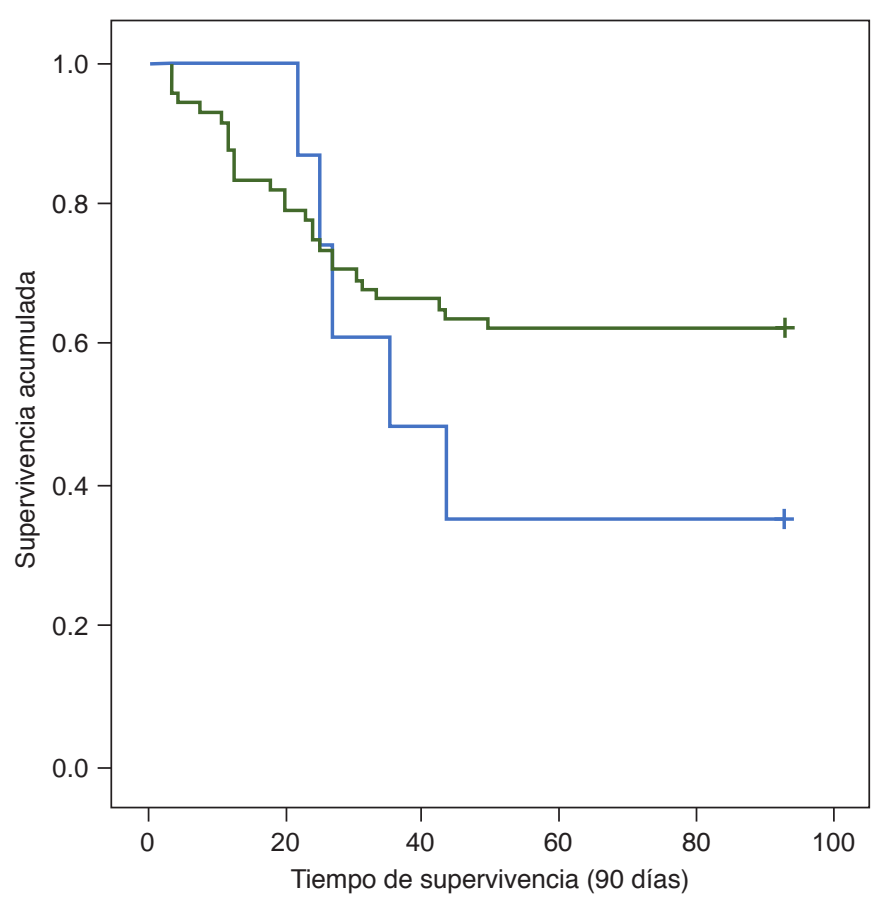

Hemocultivo periférico

$-\neg$ Con desarrollo

$\neg$ Sin desarrollo

+ Con desarrollo-censurado

Figura 2: Curva de Kaplan Meier que muestra mayor supervivencia en el grupo de pacientes con neumonía grave por SARS-CoV-2 que no presentaron desarrollo bacteriano en hemocultivos periféricos (verde) comparado con quienes sí presentaron crecimiento bacteriano (azul) $(p=0.280)$.

cia fue de $37.5 \%$, mientras que en el grupo con hemocultivos negativos (74 pacientes, 90.2\%) se registró el mayor porcentaje de supervivencia a 90 días (63.5\%) (Figura 2).

En el grupo que no tuvo crecimiento bacteriano en los hemocultivos periféricos, el tiempo promedio en que ocurrió la defunción fue de 64.1 días, mientras que en el grupo en quienes sí hubo desarrollo bacteriano fue de 52.1 días, siendo para éstos el valor de $p$ de la prueba de log rank de 0.280 , la cual al ser mayor de 0.05 indica que no hay evidencia estadísticamente significativa para rechazar la hipótesis nula de igualdad de supervivencia en ambos grupos (el comportamiento de supervivencia es el mismo en ambos grupos).

Se analizó, además, la supervivencia entre los pacientes con base en el crecimiento de microorganismos en hemocultivos centrales, de los 82 pacientes, cinco $(6.0 \%)$ presentaron crecimiento bacteriano, grupo en el que la supervivencia fue de $20 \%$, mientras que en el grupo en quienes no se presentó desarrollo bacteriano (77 pacientes, $93.9 \%$ ) se registró el mayor porcentaje de supervivencia a 90 días (63.6\%) (Figura 3).

En el grupo que no tuvo crecimiento bacteriano en los hemocultivos centrales, el tiempo promedio en que ocurrió la defunción fue de 64.3 días, mientras que en el grupo en quienes sí hubo desarrollo bacteriano fue de 42.6 días, siendo para éstos el valor de $p$ de la prueba de log rank de 0.119 , la cual al ser mayor de 0.05 indica que no hay evidencia estadísticamente significativa para rechazar la hipótesis nula de igualdad de supervivencia en ambos grupos (el comportamiento de supervivencia es el mismo en ambos grupos).

Los microorganismos más frecuentemente aislados en los hemocultivos fueron en orden de frecuencia: Stenotrophomonas maltophilia (2.4\%) y Staphylococcus epidermidis (2.4\%), seguidos de Staphylococcus hominis ssp., Pseudomonas fluorescens y Streptococcus sp.

Por último, también fue analizada la supervivencia entre los pacientes con base en el crecimiento de microorganismos en urocultivos, de los 82 pacientes, 16 (19.5\%) presentaron crecimiento bacteriano o fúngico, grupo en el que la supervivencia fue de $43.8 \%$, mientras que el grupo en que no se presentó desarrollo de microorganismos (66 pacientes, $80.4 \%$ ) tuvo el mayor porcentaje de supervivencia a 90 días (65.2\%) (Figura 4).

En el grupo que no tuvo crecimiento de microorganismos en urocultivos el tiempo promedio en que ocurrió la defunción fue de 64.3 días, mientras que en el grupo en quienes sí hubo desarrollo bacteriano o fúngico

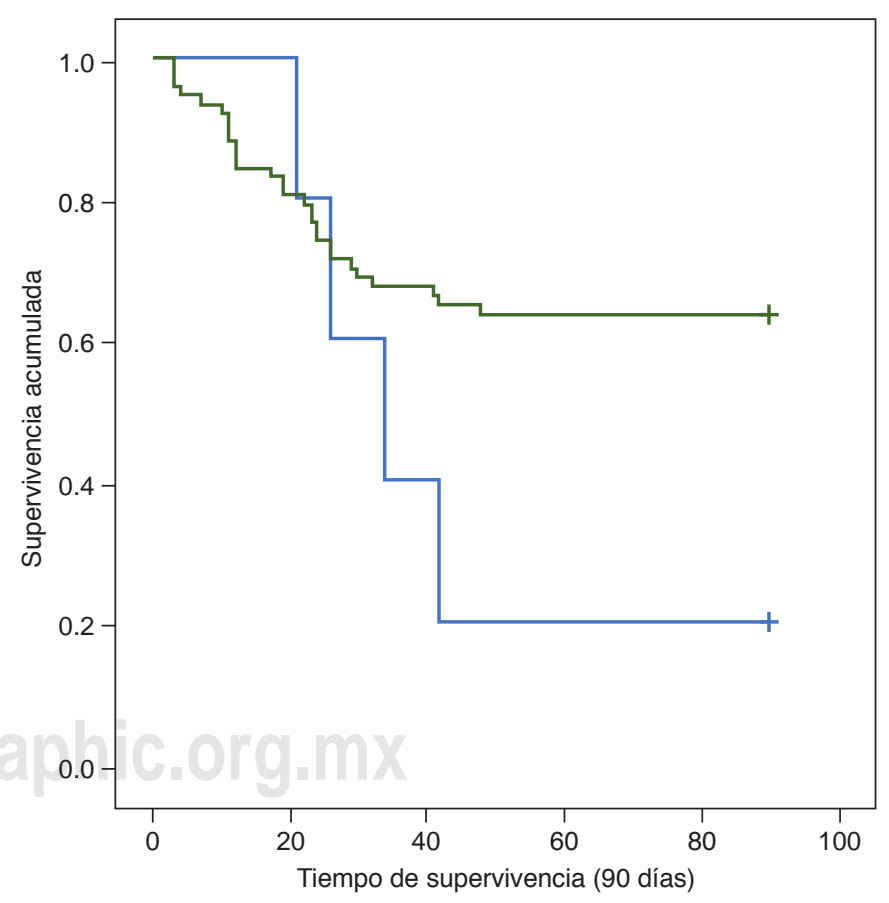

Hemocultivo central

$\neg$ Con desarrollo

- Sin desarrollo

+ Con desarrollo-censurado
+ Sin desarrollo-censurado

Figura 3: Curva de Kaplan Meier que muestra mayor supervivencia en el grupo de pacientes con neumonía grave por SARS-CoV-2 que no presentaron desarrollo bacteriano en hemocultivos centrales (verde) comparado con quienes sí presentaron crecimiento bacteriano (azul) $(p=0.119)$. 


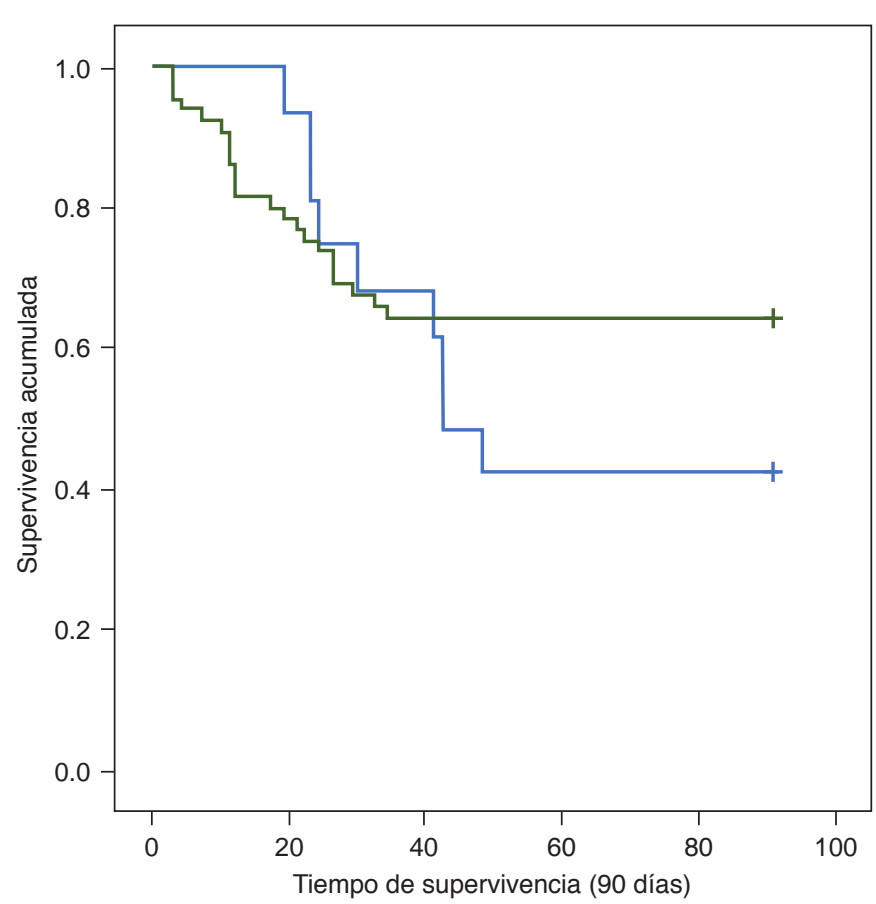

Urocultivo

$\neg$ Con desarrollo

$\neg$ Sin desarrollo

+ Con desarrollo-censurado

Figura 4: Curva de Kaplan Meier que muestra mayor supervivencia en el grupo de pacientes con neumonía grave por SARS-CoV-2 que no presentaron desarrollo de microorganismos en urocultivos (verde) comparado con quienes sí presentaron crecimiento bacteriano o fúngico (azul) $(p=0.302)$.

fue de 57.6 días, siendo para éstos el valor de $\mathrm{p}$ de la prueba de log rank de 0.302 , la cual al ser mayor de 0.05 indica que no hay evidencia estadísticamente significativa para rechazar la hipótesis nula de igualdad de supervivencia en ambos grupos (el comportamiento de supervivencia es el mismo en ambos grupos).

Los microorganismos más frecuentemente aislados en los urocultivos fueron en orden de frecuencia: Candida albicans (8.5\%), Candida glabrata (3.7\%), E. coli BLEE (2.4\%), seguidos de Acinetobacter baumannii, Acinetobacter Junii, Candida parapsilosis y Candida norvegensis.

\section{DISCUSIÓN}

En una revisión sistemática realizada por Langford y colaboradores $^{14}$ se examinaron un total de 1,308 publicaciones, analizando finalmente 24 estudios. El motivo principal de la exclusión de las demás publicaciones fue la falta de notificación de datos de coinfección bacteriana o infección bacteriana secundaria. Entre los 24 estudios, se evaluaron 3,506 casos con COVID-19 confirmado por laboratorio. Todos los estudios emplearon diseños de cohortes retrospectivos y la mayoría se llevó a cabo en Asia. Los estudios fueron realizados entre el
25 de diciembre de 2019 y el 31 de marzo de 2020. La edad media de los pacientes osciló de dos a 71 años en todos los estudios; sin embargo, la mayoría (18/24, $75 \%$ ) incluyó sólo adultos. Entre los estudios que informaron las características específicas de los pacientes, $6.4 \%$ eran fumadores, $3.2 \%$ tenía enfermedad pulmonar obstructiva crónica, 9.7\% tenía enfermedad cardiovascular y $11.5 \%$ tenía diabetes. En contraste, en nuestra población de estudio predominó la obesidad como estado comórbido (47.6\%), con una prevalencia mucho mayor de diabetes mellitus tipo 2 (37.8\%) y de enfermedades cardiovasculares como hipertensión arterial $(15.9 \%)$, registrándose cifras similares de tabaquismo (8.5\%) y de enfermedades pulmonares previas (3.7\%).

Los métodos de prueba bacteriológica que se informaron fueron cultivos respiratorios con o sin hemocultivo en 10 estudios, con amplificación de ácido nucleico respiratorio en dos estudios, y no fue especificado en 12 investigaciones. En nuestra población se analizaron además de los cultivos de secreción bronquial, hemocultivos centrales y periféricos, así como urocultivos en todos los casos. Langford y colaboradores ${ }^{14}$ a través de este metaanálisis identificaron una coinfección bacteriana en $3.5 \%$ de los pacientes y la infección bacteriana secundaria se identificó en $14.3 \%$ de los casos. Cuando se estratificó por población de pacientes, la infección bacteriana osciló entre $5.9 \%$ en todos los pacientes hospitalizados y $8.1 \%$ en aquéllos críticamente enfermos.

Nosotros encontramos una mayor prevalencia de sobreinfección bacteriana y fúngica; $25.6 \%$ de los pacientes con neumonía grave por SARS-CoV-2 tuvieron cultivos de secreción bronquial positivos, 9.7 y $6 \%$ tuvieron hemocultivos periféricos y centrales con desarrollo de crecimiento bacteriano, respectivamente, y $19.5 \%$ tuvieron urocultivos positivos.

Un estudio reciente informó una tasa de $41 \%$ de coinfección entre 17 casos ingresados en una UCI de América del Norte. ${ }^{15}$ Rawson y colaboradores publicaron los resultados de nueve investigaciones donde informan una tasa de coinfección bacteriana-fúngica de $8 \% .{ }^{13}$

Contou y su equipo informaron una tasa de $28 \%$ de coinfección bacteriana principalmente debido a Staphylococcus aureus sensible a meticilina, Haemophilus influenzae, Streptococcus pneumoniae y Enterobacteriaceae. La tasa de $28 \%$ y el espectro bacteriano observados en pacientes con COVID-19 gravemente enfermos se acercan a los informados en aquéllos críticamente enfermos con influenza estacional grave o influenza H1N1. Aislaron Pseudomonas aeruginosa en dos pacientes y Acinetobacter baumannii en uno, de los cuales ninguno presentaba factores de riesgo como inmunosupresión, tratamiento con corticoides a largo plazo, enfermedad respiratoria crónica u hospitalización reciente con tratamiento antibiótico parenteral. ${ }^{16}$ 
En nuestra población, los microorganismos más frecuentemente aislados en los cultivos de secreción bronquial fueron Pseudomona aeruginosa (6.1\%), Candida albicans (4.9\%), Acinetobacter baumannii (3.7\%), E. coli BLEE (3.7\%) y Stenotrophomonas maltophilia (2.4\%).

\section{CONCLUSIONES}

La supervivencia global en casos con neumonía grave por SARS-CoV-2 que requieren ventilación mecánica en la Unidad de Cuidados Intensivos del Centro Médico ISSEMyM Toluca es de $61 \%$, siendo mayor para aquéllos que no presentan sobreinfección pulmonar (supervivencia de $65.6 \%$ ), ni desarrollo bacteriano o fúngico en hemocultivos periféricos (supervivencia de $63.5 \%$ ) y centrales (supervivencia de $63.6 \%$ ), de igual modo presentaron una mayor supervivencia aquéllos con urocultivos negativos (65.2\%); sin embargo, sin una diferencia significativa con respecto a los grupos que sí presentaron desarrollo bacteriano o fúngico en sus cultivos ( $p$ de la prueba de log rank de 0.352, 0.280, 0.119, 0.302 respectivamente).

La sobreinfección en los casos con neumonía grave por SARS-CoV-2, al menos en nuestra investigación, no demostró ser un factor asociado a menor supervivencia, sino una consecuencia inherente a la estancia prolongada en terapia intensiva y piso de hospitalización requerida por la enfermedad per se.

Entre los pacientes con neumonía grave por SARSCoV-2, la prevalencia de sobreinfección bacteriana/ fúngica no es despreciable, pero no hay evidencia suficiente para respaldar el uso generalizado de antibióticos empíricos.

\section{REFERENCIAS}

1. Esper FP, Spahlinger T, Zhou L. Rate and influence of respiratory virus coinfection on pandemic (H1N1) influenza disease. $J$ Infect. 2011;63:260-266.

2. Klein EY, Monteforte B, Gupta A, Jiang W, May L, Hsieh YH, et al. The frequency of influenza and bacterial coinfection: a systematic review and metaanalysis. Influenza Other Respir Viruses. 2016;10:394-403.

3. Rice TW, Rubinson L, Uyeki TM, Vaughn FL, John BB, Miller RR, et al. Critical illness from 2009 pandemic influenza $A$ virus and bacterial coinfection in the United States. Crit Care Med. 2012;40:1487-1498.
4. Shah NS, Greenberg JA, McNulty MC, Gregg KS, Riddell J, Mangino JE, et al. Bacterial and viral co-infections complicating severe influenza: incidence and impact among 507 US patients, 2013-14. J Clin Virol. 2016;80:12-19.

5. Martín-Loeches I, Sanchez-Corral A, Diaz E, Granada RM, Zaragoza R, Villavicencio $\mathrm{C}$, et al. Community-acquired respiratory coinfection in critically ill patients with pandemic 2009 influenza A(H1N1) virus. Chest. 2011;139:555-562.

6. Huttner B, Catho G, Pano-Pardo JR, Pulcini C, Schouten J. COVID-19: don't neglect antimicrobial stewardship principles! Clin Microbiol Infect. 2020;26:808-810.

7. Cox MJ, Loman N, Bogaert D, O'Grady J. Co-infections: potentially lethal and unexplored in COVID-19. Lancet Microbe. 2020;1(1):e11.

8. World Health Organization. Clinical management of COVID-19 interim guidance [Internet]. Geneva, Switzerland: World Health Organization; 2020. Available in: https://apps.who.int/iris/ bitstream/handle/10665/332196/WHO-2019-nCoV-clinical2020.5-eng.pdf?sequence $=1$ \&isAllowed $=y$

9. Alhazzani W, Moller MH, Arabi YM, Loeb M, Gong MN, Fan E, et al. Surviving sepsis campaign: guidelines on the management of critically ill adults with coronavirus disease 2019 (COVID-19). Crit Care Med. 2020;48:e440-e469.

10. Yang X, Yu Y, Xu J, Shu H, Xia J, Liu H, et al. Clinical course and outcomes of critically ill patients with SARS-CoV-2 pneumonia in Wuhan, China: a single-centered, retrospective, observational study. Lancet Respir Med. 2020;8:475-481.

11. Guan WJ, Ni ZY, Hu Y, Liang WH, Ou CQ, He JX, et al. Clinical characteristics of coronavirus disease 2019 in China. N Engl J Med. 2020;382:1708-1720.

12. Cao J, Hu X, Cheng W, Yu L, Tu WJ, Liu Q. Clinical features and short-term outcomes of 18 patients with corona virus disease 2019 in intensive care unit. Intensive Care Med. 2020;46:851853.

13. Rawson TM, Moore LSP, Zhu N, Ranganathan N, Skolimowska $\mathrm{K}$, Gilchrist $\mathrm{M}$, et al. Bacterial and fungal coinfection in individuals with coronavirus: a rapid review to support COVID-19 antimicrobial prescribing. Clin Infect Dis. 2020;71:2459-2468.

14. Langford BJ, So M, Raybardhan S, Leung V, Westwood D, MacFadden DR, et al. Bacterial co-infection and secondary infection in patients with COVID-19: a living rapid review and meta-analysis. Clin Microbiol Infect. 2020;26:1622-1629. doi: 10.1016/j.cmi.2020.07.016.

15. Lehmann CJ, Pho MT, Pitrak D, Ridgway JP, Pettit NN. Community-acquired coinfection in coronavirus disease 2019: a retrospective observational experience. Clin Infect Dis. 2021;72:1450-1452. doi: 10.1093/cid/ciaa902.

16. Contou D, Claudinon A, Pajot O, Micaelo M, Longuet Flandre P, Dubert $M$, et al. Bacterial and viral co-infections in patients with severe SARS-CoV-2 pneumonia admitted to a French ICU. Ann Intensive Care. 2020;10:119.

Correspondencia:

Netzahualcóyotl González Pérez

E-mail: netza2014@outlook.com 